This article was downloaded by: [University of Michigan]

On: 4 June 2010

Access details: Access Details: [subscription number 922552469]

Publisher Routledge

Informa Ltd Registered in England and Wales Registered Number: 1072954 Registered office: Mortimer House, 3741 Mortimer Street, London W1T 3JH, UK

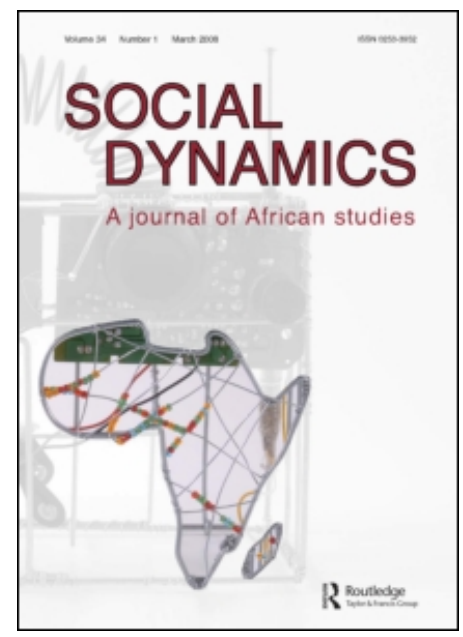

\title{
Social Dynamics
}

Publication details, including instructions for authors and subscription information:

http://www.informaworld.com/smpp/title $\sim$ content=t791476125

\section{Muthi, Medicine and Witchcraft: Regulating 'African Science' in Post- Apartheid South Africa?}

Adam Ashforth ${ }^{\mathrm{a}}$

a School of Social Science, Institute for Advanced Study, Princeton

To cite this Article Ashforth, Adam(2005) 'Muthi, Medicine and Witchcraft: Regulating 'African Science' in Post-Apartheid South Africa?', Social Dynamics, 31: 2, $211-242$

To link to this Article: DOI: $10.1080 / 02533950508628714$

URL: http://dx.doi.org/10.1080/02533950508628714

\section{PLEASE SCROLL DOWN FOR ARTICLE}

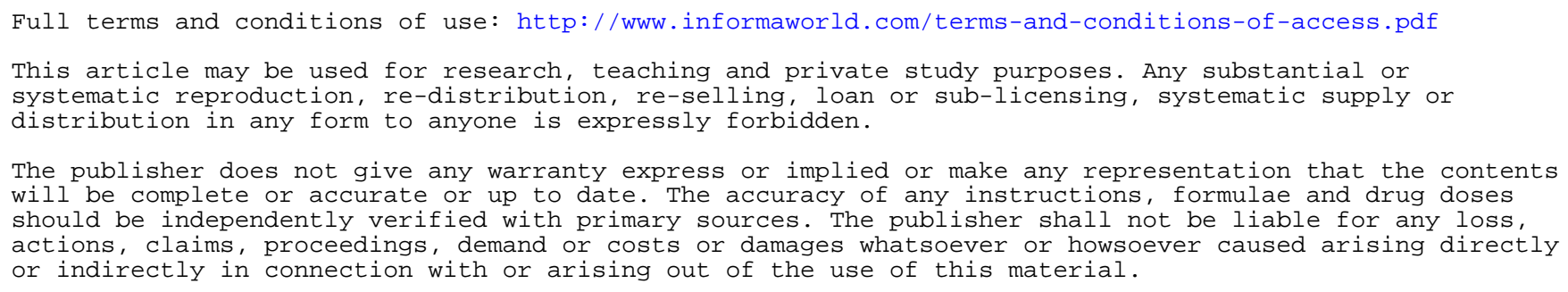

The publisher does not give any warranty express or implied or make any representation that the contents will be complete or accurate or up to date. The accuracy of any instructions, formulae and drug doses should be independently verified with primary sources. The publisher shall not be liable for any loss, actions, claims, proceedings, demand or costs or damages whatsoever or howsoever caused arising directly or indirectly in connection with or arising out of the use of this material. 


\section{Muthi, Medicine and Witchcraft: Regulating 'African Science' in Post-Apartheid South Africa?*}

\section{Adam Ashforth}

\section{Abstract}

This paper comprises extracts from Adam Ashforth's book: Witchcraft, Violence and Democracy in South Africa (Chicago University Press, 2005). It argues that the distinction between witchcraft and healing is essentially a moral one (healers and witches use supernatural forces supposedly for different ends) and that both activities fall under the rubric of 'African science'. Whereas proponents of 'Indigenous Knowledge Systems' attempt, as part of a broader cultural project, to provide 'traditional' African healing with scientific status, others - starting with Motlana's 1988 call to 'stop romanticizing the evil depredations of the sangoma' in order to free patients from the 'tyranny of superstition' - emphasise the incommensurability of traditional healing practices with science. The paper concludes with a discussion of how such incommensurability makes it very difficult, if not impossible, for the post-apartheid state to regulate 'African science'.

\section{The Dialectics of Muthi}

When people worry about 'witchcraft' in Soweto, they almost always have in mind the possibility that malicious persons are using harmful substances known generically, in the Zulu lingua franca of these parts, as muthi. When traditional healers administer aid to patients in distress, they almost always dispense substances also known generically as muthi. The term muthi (spelled

\footnotetext{
* This article comprises extracts from Adam Ashforth, Witchcraft, Violence, and Democracy in South Africa (University of Chicago Press, 2005). Copyright is held by the University of Chicago.
} 
muti in Xhosa transliterations) derives from the Nguni root -thi, signifying 'tree.' Usually translated into English as either 'medicine' or 'poison,' with the anodyne 'herbs' used in ambiguous instances, muthi refers to substances fabricated by an expert hand, substances designed by persons possessing secret knowledge to achieve either positive ends of healing, involving cleansing, strengthening, and protecting persons from evil forces, or negative ends of witcheraft, bringing illness, misfortune, and death to others or illicit wealth and power to the witch.

If the context of conversation leaves unclear whether medicine or poison is suggested, the valence of the term can be specified by reference to the colours black and white: in Zulu, umuthi omnyama (black muthi) is the harmful poison, and umuthi omhlope (white muthi) is the healing medicine. The colour of the actual substances - which are mostly shades of brown - is less important than the moral distinction between legitimate and illegitimate uses of powerful substances, although healers do place great significance upon particular colors as having healing properties (H. Ngubane, 1977: chap. 7). To understand the sorts of things people worry about when they worry about exposure to invisible evil forces in places like Soweto, it is essential to understand the various ways in which people interpret the agency inherent in substances categorised as muthi and the ways in which both human persons and invisible beings interact with them.

The distinction between healing and its antithesis, witcheraft, is an essentially moral one, based on interpretations of the motives of persons deploying muthi and the ends to which these forces are directed. Witches seeking to cause harm work with muthi as poison; healers seeking well-being work with muthi as medicine. Though directed toward health and well-being a general condition of bodily health, spiritual ease, and social harmony referred to as impilo (in Zulu; phela, Sotho) - the muthi of healers also brings death. When a healer sets out to cure a person afflicted by witchcraft, he or she will typically promise that their muthi will return the evil forces deployed by the witch to their source, thereby killing the witch. Such violence, however, is legitimate, for it is executed in the name of defense. Witches, by definition, are engaged in illegitimate uses of the powers of muthi. In everyday discourse when Sowetans refer to witchcraft, they do not usually trouble themselves with distinctions between people enjoying innate capacities to direct evil forces, people with secret knowledge about the evil uses of muthi, and people purchasing muthi from professionals for their own 
nefarious purposes. Each and every person deploying muthi for malicious or illegitimate ends - such as, say, accumulating excessive wealth or power - is spoken of as a 'witch.'

There are no limits to the possible uses of muthi other than the skill and supernatural connections of the person making and using it. Witches using muthi are said to be able to cause every disease and misfortune under the sun. Healers claim to be able to cure every disease (including AIDS, though many know better than to mention this to outsiders now) and to remedy every misfortune ever suffered.' A typical healer will advertise abilities to supply muthi to protect your house against burglars and your car against hijackers, to keep your husband faithful, to help your children pass their exams, and to keep your boss at work happy. He will also have muthi to cure your high blood pressure, diabetes, swollen ankles, and whatever else ails you. Such a healer will also know how to protect clients from police and criminals alike, though legions of the dead must be regretting the day they gave money to healers claiming to be able to turn bullets into water. ${ }^{2}$ Muthi, then, is a category of substances that act both on persons and with persons and not only human persons as ordinarily understood. Muthi also plays a part in communications between humans and spirits. Spirits both activate the powers inherent in muthi and empower these substances with new force. These propositions are treated as axiomatic by most people, including those such as born-again Christians who find the whole enterprise of traditional healing anathema and see muthi as a means of engaging with demonic forces.

Dangerous substances deployed as muthi can enter the body through the mouth in the form of food or drink, through the lungs, through contact with the skin, through sexual intercourse, and through the anus - so anyone who eats, drinks, breathes, or puts their body in contact with other persons or substances needs to be careful. The most feared mode of deployment is that of muthi in food or drink, referred to as idliso (Zulu) and sejeso (Sotho) after the verb 'to eat': ukudlisa in Zulu and ho jesa in Sotho. Other conventionally recognised modes of deploying muthi to cause harm include blowing a powder from the palm of the hand toward a victim (a gesture that also serves in everyday conversation to signify witchcraft), laying the muthi where the victim will walk over it, and placing it near the victim such as in her bed, on the roof of her house, or buried in her backyard. Burning muthi can also activate its powers. While one can protect oneself, to a certain extent, from idliso by being careful about what one consumes and avoiding offers of food 
or drink from untrustworthy sources, the other modes of deployment are more problematic, as the muthi is mostly invisible to its victim. Protection from witchcraft generally requires supernatural prophylaxis activated by a healer's muthi or a prophet's treatments.

The forces operating in muthi are said to be operative over long distances, even without any direct contact between witch and victim. Muthi can also work as a material force through the medium of a dream. A person can dream he is eating something without being aware that a witch has poisoned the food in his dream. When he awakes, the muthi will cause afflictions just as real as if the food had been consumed while awake. The ethnographic record is silent about indigenous notions of contamination through insect vectors, although in January 2000 the Sunday Times reported a story of a mob in a village in Mpumalanga attacking a traditional healer who was 'accused of bewitching mosquitoes and making them infect a client's business rivals' (Lubisi, 2000), and there is considerable lore about the use of animals and mystical creatures by witches. Nor has contamination through the eyes in the manner of the 'evil eye' so prevalent in Europe and the Mediterranean figured as a major source of harm in this region. As an active agency, muthi can produce effects of a wide variety limited only by the skill of the person making and deploying it.

The defining capacity of both the witch and the healer is the ability to interact with the invisible agency inherent in certain substances to create muthi so as to effect specific desired ends in concert with these forces. The term muthi has botanical roots. A contemporary traditional healer's apothecary, however, though dominated by natural products harvested and marketed in a multimillion-rand industry with an increasing burden on the natural environment (Mander, 1998: chap. 9, sec. 2), is by no means limited to a folkloric pharmacopeia of roots, leaves, barks, and animal products. The popular image of the traditional healer is one of a highly skilled sage dispensing secret recipes of natural herbs, recipes that have been handed down through generations and that embody the collective wisdom of indigenous knowledge. Healers, however, commonly use synthetic animal 'fats' (especially the much prized fat of the lion, imported from India) over-thecounter pharmaceuticals, and patent medicines in their healing practice (Cocks and Moller, 2002). Many also find uses for a range of industrial chemicals such as mercury, chromium, potassium permanganate, copper sulfate, and other colorful metal salts, a practice that has contributed to 
making South Africa, in the words of a leading toxicologist, a 'toxicologist's goldmine' (Stewart, 2002). Nor is the healer's nemesis, the witch, limited to the herbs available to the ancestors of old. The quest for powerful substances to both cause and alleviate misfortune cannot be limited to old recipes because in many instances the misfortunes to be caused and the sicknesses to be healed are new.

Witchcraft and healing are endeavors that privilege innovation. The key to both is knowledge. Healers and witches alike draw their powers from three possible sources: inheritance of abilities from ancestors; training by skilled masters; and direct communication with higher powers such as the ancestors, spirits (evil ones in the case of witches, of course), or the Holy Spirit. Most healers claim a little of all three in accounting for their powers. The same is presumed true of witches. But the witch's art is predicated on secrecy. The knowledge of witcheraft is known only to the witches. They may share it in secret among themselves, but it cannot be made public. If a witch were to confess to his art and make public the nature of his techniques, he would no longer be a witch and the techniques would no longer work.

The antithetical relationship between the witch and the healer in this context of secrecy places enormous significance upon the ability of the healer to demonstrate legitimate sources and purposes of his or her knowledge which, like witchcraft, must also be of a character unobtainable by the ordinary person - though the suspicion that always clings to healers that they may, despite protestations to the contrary, be capable of dark arts rarely hurts their business. In everyday Sowetan life at the turn of the twenty-first century, both the evil arts of witchcraft and the sources of healing knowledge are commonly spoken of in terms of 'African science.' The scientific basis of healing is also an article of faith in government circles. In 1998, for example, the Report of the Select Committee on Social Services on Traditional Healers of the National Council of Provinces recommended that 'this science [my emphasis] should also be developed through research and technology without necessarily westernising it' (Select Committee on Social Services, 1998: 1.1).

When specifying the abilities of 'African scientists' and identifying the kinds of interactions between the intentions of malicious persons and the capacities of substances to cause harm or the corollary capacities of healers and their herbs to cure, the field of possibility is so wide that it is virtually impossible for someone to say, 'This they cannot do' without fear of contradiction. Who can say that the foreign witch does not have access to 
muthi unheard of by the local healer? Who knows how the 'modern' witch is adapting new technologies to the pursuit of old evils? Nobody. Ordinary people do not possess the means of distinguishing among the agency inherent in the muthi (whether it be harmful or healthful), the agency of the human principal, and the agency of the victim or patient. For this they must rely upon experts, healers. And the healers, they are many.

\section{'African Science' and Witchcraft}

In everyday talk about witchcraft and healing, 'African science' serves as a basic reference point for reckonings of the potentials of secret African knowledge and skills. 'African science' in everyday talk occupies a place alongside the miracles of Scripture and the magic of what is usually referred to as Western or White science in its ability to transform the world in mysterious ways. African science and White science constitute two distinct aspects of human power to understand and shape the world. Living in a world where the miracles of computers, the remote control, and mobile telephones are everyday realities, and where images of nuclear explosions and space travel are commonplace, no one doubts the power of science to effect action at a distance and transform the world and all who live in it. Nor would many doubt the power of God and the devil to transcend the ordinary laws of physics in performing their miracles.

The fact that no one seems to know for certain how any of this is achieved is of little consequence. As a young high school student once told me: 'To my personal point of view, I think physical science, or physics, goes hand in hand with African physical science. Why I'm saying that is that physical science, well it is approved, and it is done by different nations, like Greeks, Americans. But it is in a modern way. There are labs, there are laboratories. With us, we don't have laboratories. It is done in an olden way. But it goes hand in hand.' By 'hand in hand' he meant they are equal partners in explaining and shaping the world.

Commodities embodying Western science, classes in physical science taught in schools, the prevailing imagery of industrial and technological power and the people responsible for it, and the doctors staffing clinics and hospitals have an irreducibly alien feel in this context. They are not indigenous, not African. They are 'things of Whites,' in the local parlance. Even when the scientists or doctors are black and African, they are not thought of as practicing African science. ${ }^{3}$ Most people have only the vaguest 
appreciation of what scientific inquiry entails. Pitifully few high school students graduate with adequate mastery of mathematics and science to proceed to university-level studies. Of the more than 400,000 African candidates taking the national matriculation examinations in the year 2000 , only 20,243 attempted the 'higher grade' of mathematics required for university-level science studies, and only 3,128 passed (Republic of South Africa, 2001: 13). Though the objects of 'modern technology' are ubiquitous, scientific theories and methods remain a mystery for most.

African science, that body of knowledge my young friend imagined as walking hand in hand with Western science, is equally mysterious, though for a different reason. African science is secret knowledge. This secrecy is its essential core. Some have argued that secrecy has been necessary to protect indigenous knowledge from exploitation and denigration by Whites. Participants in discussions with the Portfolio Committee on Arts, Culture, Science, and Technology on indigenous knowledge systems, for example, 'argued that the reason why indigenous people originally introduced secrecy and sacredness, was to protect indigenous knowledge from misappropriation and scrutiny by missionaries' (Portfolio Committee on Arts, 2000: para. 11.2). Be that as it may, however, secrecy is also consonant with a great many features of ritual knowledge in which mysterious powers are mobilised. The fact that African science, with its 'olden ways,' is practiced in secret broadens the field of imagination in which the potential powers of muthi and the people who deploy it play out.

Even the most passionate advocate of the power of secret African science will concede that it is less effective than Western science in building industrial technologies and national prosperity and in making wars and conquering peoples. Yet Western science seems irrelevant to the everyday misery and suffering of individuals and their families. As the young man quoted above put it, 'science can't prove anything about my self. It's got to do with the planets, the whole universe.' The healer who can throw the bones to divine the nature of a person's problems, problems created by a witch using muthi, is far more powerful when it comes to proving things about the 'self.' In speculation about the powers of witchcraft, no one will admit to having mastered African science or publicly pronounce upon its precepts or demonstrate its techniques to public scrutiny and empirical testing. To doubt that it is every bit as powerful as White science, however, is tantamount to betraying a lack of faith in Africa and Africans. When one must worry about 
the ability of others to cause harm with dangerous substances in contemporary Soweto, more often than not African science represents the source of the powers that must be reckoned with. Obviously, however, because the witchcraft that consists of 'poisoning' by muthi is practiced in secrecy, little can be publicly known about it - not so the properties of its diametric opposite: medicinal muthi.

Faith in the power of African science can best be seen in talk about the scientific status of traditional healing and indigenous medicine. When substances categorised as muthi are considered as medicine, their powers are universally assumed by black South Africans to be open to scientific confirmation. A great many black South Africans and sympathetic white people consider proving the pharmacological effectiveness of muthi part of the project of restoring the respect that should be accorded 'African culture' as an 'indigenous knowledge system' long denigrated by the West and Whites through centuries of colonisation (Serote, 1998). Although some critics argue that this research is really part of a 'biopiracy' conspiracy organised in tandem with international pharmaceutical corporations to make 'indigenous medicine knowledge' more amenable to exploitation by drug manufacturers (Rees, 1999), the press regularly carries stories with headlines such as 'Muti Passes the Science Test' (Bishop, 1997), usually quoting a traditional healer uttering words to the effect of 'we told you so.'

\section{'African Science' and 'Indigenous Knowledge Systems'}

In 1987, the eminent Sowetan medical practitioner, community leader during the 1976 Soweto Uprising, and businessman Ntatho Motlana gave an address to the graduating class of medical students at the University of the Witwatersrand. In his address, Motlana launched what has since become a much quoted denunciation of traditional healing. Motlana remains one of the few prominent Africans in South Africa willing to take a public stand skeptical of the wisdom of traditional healing. His argument in this speech is worth considering in some detail because it expresses a radically modernist perspective on traditional healing that, though still widespread (particularly among white doctors), is politically difficult, if not impossible, to articulate in these times. 
Motlana argued that 'the scientific basis for traditional medicine has not been established, that most of it was based on superstition and meaningless pseudo psychological mumbo jumbo that was often positively harmful' (1988: 17). His attack on traditional healing was launched in the aftermath of World Health Organisation (WHO) policies advocating official recognition of these healers. According to Motlana, "African health professionals trained in scientific medicine' had opposed the efforts of wellmeaning but misguided Europeans and Americans to promote the so-called indigenous doctor in framing WHO policy. He began his address by praising the European missionaries who worked to eradicate 'superstition' and by denouncing those well-intentioned liberals 'who want to take us back into the Dark Ages of Medicine by romanticizing the half naked drummer of the night.' These latter, he insisted, 'choose to forget that the so-called advanced nations of the West also passed through an age when they believed that diseases were caused by mists arising from marshes; they too believed in witchcraft, and it took centuries of turmoil, conflict, of rejecting scientific discoveries (and even executing innovators) to eradicate it' (1988: 17). People who insisted that in order to cure the 'whole person' of the 'Black African' it was necessary to 'pander to his nonsensical superstitious concerns' were attempting to 'lock the Black man permanently into the 12th century.' Traditional healers, in Motlana's view, were 'dangerous people' who should be locked up under the provisions of antiwitcheraft legislation, and he noted approvingly Samora Machel's policy of incarcerating them in reeducation camps. 'Above all,' he argued, 'health care professionals - including psychologists - must stop romanticizing the evil depredations of the sangoma' in order to 'wean our Black (and White) patients from the tyranny of superstition' (1988: 18).

Most of Motlana's address to the graduating doctors was taken up with this strident attack upon superstition, as well as its white liberal supporters. Toward the end of the speech, however, he changed the focus of his remarks somewhat and set out a project that seems remarkably prescient in the light of postapartheid experience: 'One often gets the feeling that some of my comrades in the struggle and in the professions, thrashing around for some meaningful contribution to the total sum of human achievement by Blacks, mistakenly latch onto indigenous medicine as part of that contribution. If so, let us first subject indigenous medicine to rigorous scientific examination before there is the beating of drums in the Great Hall of our University' (1988: 18). In the postapartheid era, when Motlana's former 'comrades' 
gained office in the national state (Motlana was Mandela's personal physician), they proceeded to foster efforts at 'scientific examination' of indigenous medicines. Progress in the enterprise to date has been modest. The conviction that there is a scientific basis to traditional medicine waiting to be recovered, however, remains an article of faith.

The effort to reveal the scientific foundations of traditional medicine is part of a larger cultural politics in South Africa. Beginning in the late 1990 s, African intellectuals and political leaders in South Africa began efforts, under the general rubric of the 'African Renaissance,' to foster the development of systematic knowledge about traditional medicine in terms of 'indigenous knowledge systems' (IKS). The concept of IKS owes its genesis to a confluence of intellectual and political movements in the last quarter of the twentieth century emerging in the aftermath of decolonisation out of the ecological movement's concern for sustainable environmental management, dissatisfaction with prevailing models of economic development for the Third World, and concerns with the cultural 'survival' and rights of minority indigenous peoples within larger national states. In the 1990s, the rapid development of biotechnology industries and research into scientific medical uses of traditional remedies from different parts of the globe spawned debates over questions of intellectual property and the appropriate remuneration of indigenous peoples for biological materials and knowledge exploited from their territories.

By the early twenty-first century, while much of the discussion of IKS remained inflected with countercultural romanticism about the essential unity of native peoples with nature, the acronym IKS had become part of the ready coin of international organisations and a focus of the World Intellectual Property Organization (WIPO), a United Nations intergovernmental agency, which in 1998 and 1999 sent out fact-finding missions to Asia, Africa, and Latin America. And while the origins of the idea of indigenous knowledge lay in a concern with local people's particular and culturally embedded understandings of themselves and their place in the world, 'IKS' now serves as a convenient shorthand for categorising aspects of local cultures in terms of global schemes. The World Bank, for example, issues 'Knowledge Packs' as part of its 'Indigenous Knowledge Program for Development' to 'provide users with quick access to synthesized information by country or selected thematic area' (World Bank, Sub-Saharan Africa, 2001). ${ }^{4}$ There is considerable debate in development circles over whether indigenous 
knowledge, which by definition is context specific, can be generalised in the manner of science, which, though it may have emerged in particular cultural contexts, is by definition independent of context. ${ }^{5}$

The South African discussion of IKS has been stimulated by the Portfolio Committee on Arts, Culture, Science, and Technology, chaired by the ANC poet and novelist Mongane Wally Serote. Serote is an enthusiast of the idea of IKS. In a paper presented in 1998 to a roundtable on intellectual property and indigenous peoples organised by the WIPO, Serote argued: 'Indigenous knowledge and technologies that were denied, destroyed and suppressed in the past will form the basis of our rebirth.... Indigenous knowledge, folklore and technologies have the potential to assist in the rebirth of our nation' (1998). Serote reported to the WIPO meeting that 'a programme is currently under way to harness this potential [of IKS for nation building], and the very institutions that were created to maintain apartheid the Science Councils and the black universities - have been brought into the process in a massive, visionary exercise of transformation whose outcome will be the economic empowerment of South Africa's rural poor' (1998).

To this end, the National Research Foundation was chartered in 1998 to 'support and promote research, in order to facilitate the creation of knowledge, innovation and development in all fields of science and technology, including indigenous knowledge.' In the financial year 2000/2001 R 10 million was set aside for IKS projects, although only R 5.4 million was actually allocated to fifty-four successful projects. ${ }^{6}$ The use of the term 'IKS' in postapartheid South Africa is more than a little ironic. Not only does the programme postulate notions of cultural distinctiveness that the architects of apartheid would have found most agreeable, but the programmes are advocated by African intellectuals and political leaders who consider themselves indigenous while representing (or being representative of) the majority of the population. On the one hand, these intellectuals experience aspects of the well-attested derogation of African culture by Whites and express the need to restore respect and dignity to their own traditions and culture. On the other hand, they are mostly city-dwelling educated professionals who operate in their professional lives for the most part in cultural milieus that are indistinguishable from those of their white peers but that are worlds away from the life of the rural village.

Since the late 1990s, research into the health benefits of traditional medicines has become more of a priority for the Medical Research Council of 
South Africa and university departments of pharmacy. In 1997, for example, a 'traditional medicines' (TRAMED) research project was established by the Universities of Cape Town and the Western Cape with the support of the Medical Research Council to, among other things, create a database of traditional medicines for eastern and southern Africa; conduct laboratory screening of traditional medicines for malaria and tuberculosis; and develop systems for scientific understanding of the action and uses of 'essential' traditional medicines in the prevention and treatment of disease. ${ }^{7}$

Although certain plants may have beneficial bioactive properties, identifying medicinal properties of muthi is complicated because different plants are often combined in making muthi, they are prepared in infusions and decoctions with little regard to standardised dosage, and they are administered according to methods such as drinking and regurgitating, all of which makes it virtually impossible to determine their health-giving effects with any sort of scientific rigor. Recipes for particular remedies are usually treated as trade secrets by healers and often incorporate animal products and industrial chemicals (Stewart, Steenkamp, and Zuckerman, 1998). Isihlambezo, for example, a variety of muthi prescribed for pregnant women, is widely used by African women, has some beneficial effects, but is potentially harmful to both fetus and mother (Varga and Veale, 1997). A literature review on plants used during pregnancy found that 'at least 57 different plants are used by black South African women either as antenatal remedies or, more specifically, to induce or augment labor. Among these, 16 have been reported to be toxic. The uterotonic effects of only a few of these plants have been studied' (Veale, Furman, and Oliver, 1992). A later study by Veale et al. assessed some of the plants specifically used as oxytocic remedies (to 'induce or augment labor or control postpartum bleeding') and found positive effects on the uteri of laboratory rats, but the researchers remained cautious about the dangers inherent in the difficulty of controlling dosages in practice as well as possible toxic interactions with other ingredients in the muthi (Veale et al., 1998).

The vast majority of black South Africans would applaud this endeavor to verify the scientific basis of traditional healing. In everyday parlance, such as I have heard over the years in Soweto, what the political elite call 'indigenous knowledge systems' pertaining to 'indigenous medical systems' are referred to as 'African science.' African science in everyday talk, however, is postulated not only as the scientific foundation of healing but also as the witchcraft against which healers must fight. In common talk, witches as 
well as healers are referred to as 'African scientists.' As we have seen, the dialectical nature of muthi means that for every powerful healing substance or technique an opposing evil power is presumed. The new investment in uncovering the scientific bases of traditional healing, then, also contributes to the plausibility of suppositions about the abilities of persons to cause harm to others by means of powers - 'evil forces' - categorised under the rubric of healing's antithesis: witcheraft.....

\section{Regulating Healers in the Post-Apartheid State}

Traditional healing in virtually all its forms has been illegal for more than a century in South Africa. Under the provisions of the Suppression of Witcheraft Act of 1957 (first introduced in 1895, last amended in 1970), all forms of divination are outlawed. Divination is the heart of healing in Africa; therefore, all healing is outlawed. I have been unable to find accounts of the prosecution of healers for contravening this legislation. No doubt healers have been targeted from time to time in the various districts of South Africa, probably when their activities intruded into political matters or complicated the everyday activities of white administrators. By the $1990 \mathrm{~s}$, however, healers operated without the slightest concern for contravening the Suppression of Witcheraft Act. The Health Professions Act of 1974 (Act no. 56 of 1974) requires that all health practitioners be registered with an appropriate professional governing body, of which there is none for traditional healers. More recently, the South African Medicines and Medical Devices Regulatory Authority Act of 1998 requires all medicines, including traditional medicines, to be registered with the Medicines Control Council. Despite these laws, traditional healers have only rarely been prosecuted simply for plying their trade. Nonetheless, traditional healers deeply resent their inferior status. They resent the fact that they are not accorded the same respect and government support as medical doctors, despite their conviction and that of their clients that they are providing essential services. Their clients resent the fact that they cannot obtain health insurance coverage for traditional treatments nor present employers with medical certificates from traditional healers. And the new African political elite, ever mindful of the historic denigration of African culture within previous racist regimes, is insistent that traditional knowledge and culture be accorded proper respect within this African state. 
Although the new democratically elected government is strongly committed to rectifying the situation of traditional healers, they have achieved little in their first decade of office. The difficulty of acting on these matters, despite a broad agreement on principles, reveals some of the complexities of dealing with 'evil forces' in a modern state.

Shortly after taking office in 1994, the ANC published A National Health Plan for South Africa. In conceiving the plan, the ANC drew on technical support from the World Health Organisation and UNICEF. Since the 1970 s, both of these organisations have advocated that national governments officially recognise 'traditional healers' as partners in health care and integrate 'traditional medicine' into Western biomedical systems. In the ANC's plan, the new government promised to 'seek to establish appropriate mechanisms that will lead to the integration of traditional and other complementary healers into the National Health Service' (African National Congress, 1994: chap. 1).

It is unclear from the plan exactly what is meant by 'integration.' Many writers on the subject of relations between medical systems have suggested that three broad possibilities exist for policy on the matter: full integration (in which case the question of the status of traditional healers within the health system arises: equal or subordinate to medical doctors?); cooperation, where a degree of common purpose is developed between different kinds of practitioners while each sector retains independence; and parallelism, where each remains distinct and independent of the other. The ANC plan at different points seems to suggest both integration and cooperation. ${ }^{8}$ The ANC's National Health Plan also promised that the government would 'investigate the safety and potential benefit of traditional drugs,' while 'fostering liaison and cooperation with traditional healers.' The overall aim was to make 'traditional healing . . . an integral and recognised part of health care in South Africa. Consumers will be allowed to choose whom to consult for their health care, and legislation will be changed to facilitate controlled use of traditional practitioners' (African National Congress, 1994: chap. 3).

Much of the language of this National Health Plan bears the hallmark of a liberation movement gaining office in a state for the first time and determined to set the world to rights at once. ANC offices around the country are littered with thousands of such noble plans gathering dust as the party gets on with the business of governing. The idea of legislating 'controlled use of 
traditional practitioners,' for example, is pure fantasy. None of the policy documents on traditional healing provide answers to the question of why, after a century of being outlawed, healers would willingly submit to being 'controlled' by Department of Health bureaucrats. The conceptual framework of this National Health Plan, however, is worth examining in detail, as it reveals the orthodoxies of political thinking about issues of traditional healing in postapartheid South Africa. It also reveals why regulation of the industry that manages problems of witchcraft will be difficult to achieve.

Underpinning the plan's policies regarding 'traditional practitioners' were the following 'tenets':

People have the right of access to traditional practitioners as part of their cultural heritage and belief system.

There are numerous advantages in cooperation and liaison between allopathic and traditional health practitioners and interaction will thus be fostered.

Traditional practitioners often have greater accessibility and acceptability than the modern health sector and this will be used to promote good health for all.

Traditional practitioners will be controlled by a recognised and accepted body so that harmful practises can be eliminated and the profession promoted.

Mutual education between the two health systems will take place so that all practitioners can be enriched in their health practises. (African National Congress, 1994: chap. 3)

The elementary presumptions of this plan, then, are that there exist two distinct 'health systems' - one 'modern' and 'allopathic' the other 'traditional' and part of an African 'cultural heritage and belief system' which can be integrated into a single national health care system under the auspices of the state. To facilitate the policy of integrating the systems, the ANC proposed that negotiations take place between government representatives and traditional practitioners, that legislation be enacted to change the 'position and status' of healers, that interaction between practitioners from different health systems be encouraged, that training programmes be initiated, and that a 'regulatory body for traditional medicine' be established (African National Congress, 1994: chap. 3).

The goals and methods of the National Health Plan at first glance seem entirely laudable. Clearly, since many, if not most, black South Africans engage the services of traditional healers from time to time, a democratic government cannot deny them this right. Indeed, coming to power after decades of struggle against a regime that seemed intent upon denigrating the culture of black people - albeit while claiming to respect that of 'the Bantu' - 
the ANC government was keen to insist that the proper status of African tradition be respected. A government committed to the multicultural principles enshrined in the South African Constitution must be prepared to respect the practices of healing widespread among the population. All of this may be laudable, but it ignores some fundamental questions, such as whether or not there are indeed two systems of health care, in what sense or senses traditional practitioners are in fact traditional, in what sense or senses they are health care practitioners (as distinct from, say, religious or spiritual leaders), and to what extent the forms of knowledge and authority underpinning traditional healing are compatible with those institutionalised within modern bureaucratic states. This last point is especially important because a large part of the work of healing involves - in the words of the healers' representatives reporting to the Portfolio Committee on Arts, Culture, Science, and Technology - battling against evil forces of witchcraft.

\section{Healing and Authority}

Prospects for state regulation of the healing industry hinge upon the ability of public officials to find ways of connecting principles of authority operative within the state to those operating in the world of healing in all the varieties that are practiced. Policy makers seeking to devise ways for the state to recognise the legitimacy of traditional healing are confounded by the fact that while there are many revered practitioners of what they refer to as 'traditional medicine,' there are no indigenous written or scholarly traditions in this field. Most of the literature on traditional healing in South Africa has been written by white missionaries, social scientists, and medical practitioners, most of whom write within the disciplines of academic scholarship. ${ }^{9}$ While much of this literature is informative and sympathetic, it hardly serves the purpose of building officially recognised training programmes or registers for traditional healers. Compared to the body of literature developed by anthropologists, lawyers, officials, and traditional leaders in the field of customary law (Bekker, 1989), which has long been recognised (and rewritten) by the state, the material on medical practice would be a flimsy foundation on which to build an edifice of public health administration. ${ }^{10}$ Nonetheless, the goal of integrating 'medical systems' remains official government policy.

Progress on the tasks of recognising and regulating healers has been slow. It seems there are some basic impediments to the institutionalisation of African healing traditions within a modern national state. In 1995, the 
ministers of health in the national and provincial governments agreed to conduct hearings into traditional healing with a view to affording healers official recognition (E. Pretorius, 1999). In 1996, the Interim Co-ordinating Committee for Traditional Medical Practitioners' Associations made a presentation to the National Council of Provinces 'appealing for formal recognition of their system of medicine.' The healers told Parliament that their 'dignity had been eroded by the colonial and apartheid powers' and reminded them that the official policies of both the ANC and the Department of Health called for official recognition. The Department of Health, however, reported that they were unable to make policy in this regard, as they lacked information and were confounded by the 'apparent division within this profession' (Select Committee on Social Services, 1998: 4). In response to these appeals, hearings were held in 1997 and 1998 under the auspices of the Select Committee on Social Services of the National Council of Provinces and the Portfolio Committee on Health of the National Assembly.

In August 1998, the Select Committee on Social Services presented its report to Parliament. They recommended the creation of a statutory council for traditional healers similar to the bodies regulating other forms of medical practice. The 'broad functions' of this body were to be as follows:

1. Registration of all qualifying traditional healers.

2. Promotion of training, research, professionalism and the creation of a traditional medicine data base.

3. Development of an ethical code of conduct and the maintenance of discipline within the profession.

4. Establishment of norms and standards with regard to the practice of traditional healing, including regulating the issuing of medical certificates and tariff levels.

5. Facilitating co-operation among traditional healers, allopathic medical professionals and the government.

6. Regulating anything incidental to traditional medical practice. (Select Committee on Social Services, 1998: 5)

In short, the committee did little more than reiterate the policy articulated in the ANC's National Health Plan four years earlier. They gave no indication as to how relevant qualifications might be decided for inclusion in the register or how standards might be maintained other than to pass the task onto another proposed consultative body. of healers:

The report recommended recognition of the following four categories 
(a) Inyanga (herbalist or traditional doctor). This is usually a person who uses herbal and other medicinal preparations for treating disease.

(b) Sangoma (diviners). They are trained to communicate with and utilise the powers of ancestors in diagnosing a disease or mishap.

(c) Traditional birth attendants (Ababelekisi). They are usually elderly women who have been midwives for years and are highly respected for their obstetric expertise.

(d) Traditional surgeons (iingcibi). They are usually trained men with experience in conducting traditional circumcision. (Select Committee on Social Services, 1998: 6)

The committee offers no guidance as to how the training in communicating and utilising powers of ancestors might be evaluated by the proposed statutory council. Birth attendants and circumcision surgeons are relatively simple to integrate into the medical system because their work is limited and nothing in the traditions they uphold is incompatible with basic medical principles. Official recognition of their activities, therefore, merely requires promoting proper education for practitioners in the basics of hygiene (such as requiring iincibi to use a fresh sterile blade on each initiate) and the ability to quickly recognise complications requiring medical attention. In recent years a number of well-publicised fatalities at circumcision schools have resulted in demands for closer official scrutiny, and several traditional surgeons have been arrested for running unregistered schools where initiates have died. A somewhat more complicated matter involving negotiation between legal cultures embodying different principles concerning the nature of childhood and consent arises from the fact that the circumcision rituals marking the passage of boys to men require a degree of hardship that has always been accompanied by a risk of death: the men now running the circumcision schools risk charges of 'child abuse.' Teenage boys from schools where teachers are no longer allowed to use corporal punishment sometimes find it difficult to adjust to the strenuous discipline of the circumcision school. These issues, however, can be sorted out quite satisfactorily on a case-by-case basis. ${ }^{11}$

Inyangas and sangomas, however, constitute a far more difficult problem for the state because much of their practice is founded on radically different principles from those embodied in biomedical science. Moreover, the committee's distinction between inyangas as herbalists and sangomas as diviners is deeply problematic. Implicit in the description of healing categories presented in the committee's report is a model of functional differentiation of professions and modes of training that is thoroughly 
Western and modernist in conception and that ignores the possibility of unseen evil forces acting in both the etiology and the treatment of disease. Such a model presumes that matters such as qualifications, standards, fees, and codes of conduct are products of hierarchical social authority and can be made, therefore, subject to regulation by the state. When a draft Traditional Health Practitioners Bill was finally published in the Government Gazette on April 14, 2003, after nearly ten years of formulation and consultation, the proposed legislation was an almost identical transcript of the Health Professions Act (Act no. 56 of 1974). The draft bill avoids mention of inyangas and sangomas or any other category of healer and the various categories of evil forces they see themselves contending with, 'defining 'traditional health practice' instead as

the performance of a function, activity, process or service that includes the utilization of a traditional medicine or a traditional practice and which has as its object:

(a) the maintenance or restoration of physical or mental health or function; or

(b) the diagnosis, treatment or prevention of a physical or mental illness; or

(c) the rehabilitation of a person so that he or she may resume normal functioning within the family or community;

(d) the physical or mental preparation of an individual for puberty, adulthood, pregnancy, childbirth, and death.

The main purpose of the bill is to establish procedures for the minister of health to constitute a Council of Traditional Health Care Practitioners and to outline procedures by which this council is supposed to register and regulate healers.

Despite the fact that they number in the hundreds of thousands and perform services very similar to those of traditional healers, the report of the Select Committee on Social Services rejected suggestions that 'spiritual healers (abathandazi)' be included in the register, because the committee was 'of the view that ... they are not traditional in nature and their training and accreditation is unclear and ill-defined' (1998: 6). Considering that the training of healers includes communicating with the spirits of the dead and that the procedures used by many healers are constantly being updated and changed, the committee was perhaps being somewhat rash in the judgment that their training was more clearly defined than that of spiritual healers in general. In any event, as officials of the Department of Health discovered when they began discussions of questions of training and certification with 
healers' organisations, no consensus was possible on the question of what qualifies a person to heal. ${ }^{12}$

The powers underpinning virtually every kind of nonmedical healing in South Africa derive from personal relationships with ancestors and other spiritual beings. While there may appear to be regularities and patterns in practice, these patterns are of an entirely different order from those that emerge in systems governed by authoritative institutions such as those of biomedical science and the medical professions. While the policy makers might want to institute more professionalisation within the traditional-healing 'sector,' if they were serious about engaging with the authority structures of such healing practices in the manner understood by the practitioners themselves, they would have to propose a mode of negotiation, not just with 'stakeholders' in the sector, but with the ancestors and spirits on whose behalf most of the stakeholders practice. This would not be a simple undertaking, but the policy makers, in their insistence that traditional health care can be regulated by institutions constituted along lines identical to those regulating the medical professions, seem to be assuming that authority deriving from connection with ancestors and other invisible beings can be treated as if coterminous with the secular authority of communities, professions, and the state.

Traditional healers do not operate completely outside structures of ordinary social authority. Ngoma rituals, for example, are regulated to some extent within networks of diviners centered on senior healers who teach and initiate others into the calling (Green, Zokwe, and Dupree, 1995; H. Ngubane, 1981). Although a senior healer could possibly initiate a hundred or more sangomas over the course of a long career, these networks are limited in extent. Harriet Ngubane estimated in 1981 that an average Zulu diviner might be in contact with some four hundred fellow diviners from all over the subcontinent over a three- to five-year period (1981: 364). During the process of ukuthwasa the senior serves merely as a guide in assisting the afflicted initiate in developing his own relationship with tutelary spirits, who in turn empower his healing practice. Although the influence of seniors and colleagues no doubt remains strong during a sangoma's career, and although there are various recognised grades and statuses among sangomas, in theory she or he is dependent for healing power only upon personal spirits. This makes these networks extremely fissiparous. Indeed, I have known healers to boast of having broken away from the senior to whom they were apprenticed 
and remaining independent of all other human authorities as a way of emphasising their primary subjection to spiritual power and thus their extraordinary capacity to heal.

The authority structures that emerge within networks of sangomas, however, are not hierarchies of the sort that are utilised in modern Western states for certifying and regulating healing practice. Although senior healers exercise a great deal of authority over initiates, there is no power on earth that can prevent people from becoming healers if they feel their ancestors so desire, or prevent them from practicing in ways they believe their ancestors demand. Nor can any person say without fear of contradiction that a particular healer's call is not genuine. It is not impossible to imagine, however, these networks of healers being organised into representative organisations capable of accrediting members such that the entire institution might be regulated more formally. This is the hope underlying current government policy. The proliferation of associations, councils, and advocacy groups representing healers over the past decade in anticipation of a new legal framework, however, suggests that a fertile field for political action exists in this domain. Some estimates put the number of such associations at more than 150 (Pretorius, 1999). ${ }^{13}$ The heart of the matter that representatives of the state feel called upon to resolve, however, the problem of distinguishing genuine healers from charlatans and regulating the use of 'harmful medicines,' remains intractable.

The figure of the sagacious sangoma, guardian of spiritual tradition participating in age-old rituals of the ancestors, dominates the image of traditional healing in public discourse in contemporary South Africa. The major part of the work of healing illness and misfortune in contemporary South Africa, however, is actually carried on outside this domain. Most healing and health maintenance work is done at home, without professional supervision, by people medicating themselves and their families and friends with substances obtained from grocery stores, clinics, hospitals, inyangas' 'surgeries,' pharmacies, 'African chemist' shops, and streetside muthi vendors. In addition to self-medication and ministration, people draw upon an array of nonmedical practitioners and religious entrepreneurs of the most diverse kinds, who offer cures for every ailment and 'medicine' to solve every imaginable problem of life. Many of these problems - like the need of students to obtain muthi guaranteeing success in examinations; or the need of gamblers for success in the Lotto - would have been unrecognisable to their 
ancestors. The title inyanga is commonly given to all healers who are in neither medical nor religious institutions. This is a crowded marketplace.

Inyangas typically claim two distinct grounds for their healing abilities. On the one hand, they insist on the length and rigor of their training with a master healer. On the other, they claim that their skills with muthi derive from their ancestors - either through inheritance of an innate capacity or through direct instruction by means of dreams or both. Judging from the fragmentary information available in the literature on medical mishaps and clinical syndromes associated with traditional healing, the substances and practices of inyangas are no longer based solely upon a traditional herbal apothecary. As one of the leading toxicologists of South Africa has recently argued: 'there is a need to explode the myth that all of these [traditional remedies] are safe' (Stewart, Steenkamp, and Zuckerman, 1998: 513). The facts that healers operate with a radically different concept of etiology and a vastly more expansive interpretation of the agency of substances than is common in pharmacology make it difficult to connect scientific interpretations of medicinal substances with popular healing practices, particularly those geared toward protection from witchcraft. When policy makers invoke the 'traditional healer' or 'traditional medical practitioner' in their deliberations, they tend to conjure into being the sangoma figure representing the wisdom of the ages. Meanwhile, in the townships, squatter camps, and dilapidated slums of the inner cities, so-called inyangas are dispensing their muthi without restraint.

The term inyanga signifies nothing as consistent or orderly as the ngoma cult. It is this domain of healing work that policy makers worry about when they talk about integrating 'health systems,' restraining 'harmful practices,' and regulating the training, practice, and remuneration of African 'health professions.' In the discourses of health policy, at least among those who are sympathetic to the enterprise of traditional healing (which is the vast majority of black South Africans and not a few white people), inyangas are seen as 'herbalists' dispensing natural healing products based upon ancient wisdom. And this wisdom is widely considered to constitute a system of knowledge which, in the interests of multicultural justice, must be considered equally valuable as any other, particularly that of 'Western' science. For policy makers concerned with traditional healing, particularly those who are sympathetic to the image of the healer as sage, the principal issue is the task of identifying and prosecuting 'charlatans.' 
Distinguishing between the charlatan and the sage, however, is complicated. In popular discourse in places like Soweto, inyangas are seen as African scientists whose secret knowledge allows them to perform 'miracles.' These miracles can be either miracles of harm and death in the manner spoken of as witchcraft or miracles of healing. The only charlatans in this business are those whose miracles fail to happen after they have taken their clients' money. Even the relatively straightforward issue of tariffs and fees, which government policy suggests should be regulated, are related to the dignity and authority of invisible beings. For most healers, the fee is stipulated as a token of respect to their ancestors and is not spoken of as an economic arrangement at all. Of course, if the ancestors are powerful and much in demand, the fee will be high. ${ }^{14}$ Discussions of the importance of recognising traditional healing often refer to its cost advantage in relation to Western medicine as a reason for encouraging official recognition and generally developing the practice.

Questions of cost relating to traditional healing, however, are not at all straightforward. While it may well be the case that the costs of establishing a modern medical practice are greater than those involved in a traditional practice, it is by no means certain that the costs to patients will always be less. Consultations with traditional healers are almost always an ongoing process, more like prolonged psychotherapy in their general structure than a visit to the general practitioner. Cure is never final. There is always some other detail needing attention, resulting in further expense. Moreover, as the practice of healing usually involves mending relations with family, both living and dead, while overcoming forces of evil dispatched by others, the costs of healing include things such as feasts for ancestors and their hungry descendants and reinforcing protections against witches. Such procedures can easily run into the thousands of rand. In fact, without spending thousands, it is impossible to be assured that everything that could be done to deal with a particular case of misfortune has been done. At the end of the day, if misfortunes persist, a whole new regime of treatment, even a new healer, and more expense might be required.

The Select Committee on Social Services inquiry into traditional healing noted that the 'practice of traditional medicine is officially outlawed' under provisions of the Health Professions Act of 1974. It also noted that until the end of apartheid, 'traditional healers were not only degraded and dehumanised but were branded as witches.' Yet, despite this outlawing, 'large 
numbers of Africans continued their belief in and trust of traditional medicines' (Select Committee on Social Services, 1998: 3). What the committee did not investigate, however, was how healers, having survived decades of official repression, might be induced to cooperate with authorities of the state in a system of regulation and registration that could in theory disqualify them from practicing a calling that had come from their ancestors. Nor does the report or the draft bill of 2003 offer any guidance as to how, if the qualifications for healing include such things as communicating with ancestors, the process of appointment to the statutory council can be guaranteed as 'transparent and democratic' (Select Committee on Social Services, 1998: 6). In its drive to find a way of according respect to a certain official model of 'tradition,' the committee neglected the fact that in South Africa there is a large and energetic population of nonmedical therapists practicing varieties of healing they are pleased to call, among other things, 'herbal,' 'spiritual,' and 'traditional' who are not Africans in the way the present regime understands that term. After the report was tabled in 1998, many of the white healers moved to develop common cause with African traditional healers' associations to lobby jointly for official recognition. ${ }^{15}$

Given that for the past decade the Department of Health has been preoccupied with the AIDS epidemic at the same time as much of the infrastructure of the allopathic medical system has been collapsing, the failure to make progress in regulating traditional healing is not surprising. The AIDS epidemic, however, has also heightened the perception of the need to integrate traditional healers into the public health endeavor. In practice, when policy makers devise plans for the health system, they have mostly ignored traditional healing entirely or else have situated nonmedical healers in a clearly subordinate role. ${ }^{16}$ Generally, such plans call for programmes to train healers to recognise symptoms of AIDS and illnesses such as tuberculosis, as well as other sexually transmitted diseases, in order to facilitate referrals to biomedical practitioners; they treat traditional healing as a subsidiary activity to Western medicine. ${ }^{17}$ However, as illnesses associated with AIDS become more widespread, demand for the services of healers and their remedies is likely to increase substantially. Policing claims for having discovered cures for AIDS will prove a taxing task for authorities.

In the first decade of democratic rule, the most significant legislation pertaining to traditional healers has been the South African Medicines and Medical Devices Regulatory Authority Act (Act no. 132 of 1998), which 
includes 'traditional medicines' under the category 'complementary medicines.' This act provides for the regulation and registration of all medicines intended for human and animal use. Under its terms, muthi must be approved by the Medicines Control Council, who are appointed by the minister of health, and sold with full disclosure of ingredients. The provision has simply been ignored. Healers dispense their remedies without giving a thought to the fact that they are now required to submit their healing potions to the scrutiny of the Medicines Control Council. ${ }^{18}$ As the AIDS crisis grows, public interest in traditional muthi as remedies is increasing, as are opportunities to profit from their manufacture and sale. There is no sign of an effective regulatory system emerging.

Given that the final authority for healers' activities and the source of their healing gifts lie in the domain of invisible beings, and considering that many of the ailments they treat are considered to have an origin in domains of occult forces, it is difficult to see how bureaucratic regulation can ever be fully effective. Regulatory bodies, however, especially if they control significant financial resources and disciplinary powers, will certainly spawn a whole new field of political activity as groups struggle for control of these resources. The new legislation will also empower the minister of health to grant certain healers an official imprimatur. But while the rhetoric of policy makers invokes models of authority emphasising the creation of systematic bureaucratic regulation for traditional healing, the most likely prospect for this sector is a continuation of the present unregulated market for healing services coupled with a smaller sector of healers who win control of state resources.

Adam Ashforth is a Visiting Associate Professor of Social Science at the School of Social Science, Institute for Advanced Study, Princeton. He is the author of Madumo, A Man Bewitched (Chicago: University of Chicago Press and Cape Town: David Philip, 2000) as well as Witchcraft, Violence, and Democracy in South Africa (Chicago and London: University of Chicago Press, 2005). His email address is Ashforth@ias.edu. 


\section{References}

African National Congress. 1994. A National Health Plan for South Africa. (Prepared by the ANC with the technical support of WHO and UNICEF.) Johannesburg: African National Congress.

Ashton, E. H. 1943. Medicine, Magic, and Sorcery among the Southern Sotho. Cape Town: University of Cape Town.

Becker, Heike. 2001. 'I Am the Man': Historical and Contemporary Perspectives on Masculinities in Northern Namibia. Paper presented at the 'AIDS in Context' conference, University of the Witwatersrand, April 4.

Bishop, Craig. 1997. Muti Passes the Science Test. Electronic Mail and Guardian (Johannesburg) Internet ed., October 2, 1997. http://www.web.co.za/mg/news/97oct2/200c-muti.html.

Chanock, Martin. 2001. The Making of South African Legal Culture, 1902-1936: Fear, Favour, and Prejudice. Cambridge: Cambridge University Press.

Cocks, Michelle, and Anthony Dold. 2000. The Role of 'African Chemists' in the Health Care System of the Eastern Cape Province of South Africa. Social Science and Medicine 51(10): 1505-1515.

Cocks, Michelle, and V. Moller. 2002. Use of Indigenous and Indigenised Medicines to Enhance Personal Well-Being: A South African Case Study. Social Science and Medicine 54(3): 387-397.

Conco, W. Z. 1972. The African Bantu Traditional Practice of Medicine: Some Preliminary Observations. Social Science and Medicine 6: 283-322.

Department of Health. 1999. Health Sector Strategic Framework, 1999-2004. Pretoria. http://196.36.153.56/doh/docs/policy/framewrk/.

Department of Health. 2000. HIV/AIDS/STD Strategic Plan for South Africa, 2000-2005. Pretoria. http://196.36.153.56/doh/docs/index.html.

Drewes, Siegfried, and Marion Horn. 2002. The African Potato Hypoxis Hemerocallidea

(Hypoxidacea): Myth or Miracle Muthi.

http://www.akita.co.za/mnp/africanpotato.htm.

Ellen, Roy, and Holly Harris. 1996. Concepts of Indigenous Environmental Knowledge in Scientific and Development Studies Literature: A Critical Assessment. Paper presented at the East-West Environmental Linkages Network Workshop 3, Canterbury, May 8-10.

Ellen, Roy, and Holly Harris . 2000. Introduction to Indigenous Environmental Knowledge and Its Transformation: Critical Anthropological Perspectives, ed. Roy Ellen and Holly Harris. Amsterdam: Harwood.

Elliot, J. 1984. Black Medical Students and African Cosmological Beliefs. Africa Insight 14(2): 109-112. 
Farrand, Dorothy. 1980. An Analysis of Traditional Healing in Suburban Johannesburg. MA thesis, Department of Psychology, University of the Witwatersrand.

Freeman, M., and M. Motsei. 1992. Planning Health Care in South Africa--Is There a Role for Traditional Healers? Social Science and Medicine 34(11): 1183-1190.

Green, E. C., B. Zokwe, and J. D. Dupree. 1995. The Experience of an AIDS Prevention Program Focused on South African Traditional Healers. Social Science and Medicine 40(4): 503-515.

Gumede, M. 1990. Traditional Healers: A Medical Practitioner's Perspective. Johannesburg: Skotaville.

Hahlo, H. R., and Ellison Kahn. 1960. Recognition of Native Law and Creation of Native Courts. In The Union of South Africa: The Development of Its Laws and Constitution, by H. R. Hahlo and Ellison Kahn. London: Steven and Sons.

Hammond-Tooke, David, 1989. Rituals and Medicines: Indigenous Healing in South Africa. Johannesburg: AD Donker.

Hammond-Tooke, W. David. 1970. Urbanization and the Meaning of Misfortune. Africa 40(1): 25-38.

Hewson, Mariana G. 1998. Traditional Healers in Southern Africa. Annals of Internal Medicine 128: 1029-1034. http://www.acponline.org/journals/annals/15jun98/soafrica.htm.

Hopa, M., L. C. Simbayin, and C. D. Du Toit. 1998. Perceptions on Integration of Traditional and Western Healing in the New South Africa. South African Journal of Psychology 28(1): 8-15.

Kiernan, James P. 1990b. The Production and Management of Therapeutic Power in Zionist Churches within a Zulu City. Lewiston: Edwin Mellen.

Leonard, Kenneth L. 2001a. African Traditional Healers: The Economics of Healing. IKNotes 32. http://www.worldbank.org/afr/ik/iknt32.pdf.

Leonard, Kenneth L. 2001b. African Traditional Healers: Incentives and Skill in Health Care Delivery. Discussion Papers Series 9798-13, Department of Economics, Columbia University.

Lubisi, Dumisani. 2000. Mob Goes Wild after Mozzies Are 'Bewitched.' Sunday Times (Johannesburg), January 16, p. 16.

Majeke, A. M. S. 2002. Towards a Culture-Based Foundation for Indigenous Knowledge Systems in the Field of Custom and Law. In Odora Hoppers, Catherine. 2002. Indigenous Knowledge and the Integration of Knowledge Systems: Towards a Philosophy of Articulation. Cape Town: New Africa Books.

Malan, Rian. 1990. My Traitor's Heart: A South African Exile Returns to Face His Country, His Tribe, and His Conscience. New York: Atlantic Monthly Press.

Mander, Myles. 1998. Marketing of Indigenous Medicinal Plants in South Africa: A Case Study in Kwazulu-Natal. Food and Agriculture Organization, Rome. http://www.fao.org/docrep/W9195E/w9195e00.htm. 
Motlana, N. 1988. The Tyranny of Superstition. Nursing RSA 3(1): 17-18.

Mutwa, Credo Vusa'mazulu. 1969. My People: The Writings of a Zulu Witchdoctor. London: Anthony Blond.

Ngubane, Harriet. 1977. Body and Mind in Zulu Medicine: An Ethnography of Health and Disease in Nyuswa-Zulu Thought and Practice. London: Academic Press.

Ngubane, Harriet. 1981. Clinical Practice and Organization of Indigenous Healers in South Africa. Social Science and Medicine 15(3): 361-366.

Odora Hoppers, Catherine. 2000. Indigenous Knowledge and the Integration of Knowledge Systems: Towards a Conceptual and Methodological Framework. Discussion document. Pretoria: Human Sciences Research Council. http://www.dst.gov.za/programmes/indigenous_knowledge/iksdoc.pdf.

Odora Hoppers, Catherine. 2002. Indigenous Knowledge and the Integration of Knowledge Systems: Towards a Philosophy of Articulation. Cape Town: New Africa Books.

Oosthuizen, Gerhardus. 1992. The Healer-Prophet in Afro-Christian Churches. Leiden: E. J. Brill.

Oosthuizen, Gerhardus C., S. D. Edwards, W. H. Wessels, and I. Hexham. 1989. Afro-Christian Religion and Healing in Southern Africa. African Studies, vol. 8. Lewiston: Edwin Mellen.

Peltzer, Karl. 2001. Attitudes of Physicians toward Traditional Healing, Faith Healing and Alternative Medicine in Rural South Africa. Medicine Journal (Internet Issue). http://www.medpharm.co.za/tmj/2001/aug_01/attitudes.html.

Portfolio Committee on Arts, Culture, Science, and Technology. 2000. Report of the Portfolio Committee on Arts, Culture, Science, and Technology on Indigenous Knowledge Systems. National Assembly, Cape Town. http://www.polity.org.za/govdocs/reports/committees/newreports.htm.

Pretorius, Engela 1999. Traditional Healers. In South African Health Review, 1999, ed. Nicholas Crisp and Antoinette Ntuli. Durban: Health Systems Trust.

Ramphele, Mamphela. 2002. Steering by the Stars: Being Young in South Africa. Cape Town: Tafelberg.

Rees, Anthony. 1999. Biodiversity and Intellectual Property Rights: Implications for Indigenous People of South Africa. May 4, 1999. Traditional Healers Organization for Africa. http://www.mamiwata,com/rights.html.

Republic of South Africa. 2001. National Strategy for Mathematics, Science, and Technology Education in General and Further Education. Department of Education, Pretoria. http://education.pwv.gov.za/DoE_Sites/Maths\%20and\%20Science/Final-doc.pdf.

Rouse, Jonathon. 1999. Global Dissemination of Indigenous Knowledge: Contradiction, or The Way forward? http://www.worldbank.org/afr/ik/global_ik990615.htm

Select Committee on Social Services. 1998. Report of the Select Committee on Social Services on Traditional Healers. No. 144-1998, August 4. Parliament of the Republic of South 
Africa, Cape Town. Hansard.

www.polity.org.za/govdocs/parliament/papers/ta/1998/tal111.html.

Serote, Mongane Wally. 1998. Initiatives for Protection of Rights of Holders of Traditional

Knowledge, Indigenous Peoples and Local Communities. WIPO/INDIP/RT/98/4C,

World Intellectual Property Organization, Geneva.

http://www.wipo.org/eng/meetings/1998/indip/rt98_4c.htm.

Stewart, M. J. 2002. South Africa: A Toxicologist's Goldmine. Therapeutic Drug Monitoring 24(1): 172-177.

Stewart, M. J., V. Steenkamp, and M. Zuckerman. 1998. The Toxicology of African Herbal Remedies. Therapeutic Drug Monitoring 20(5): 510-516.

Thamba Administrators. 2001. The Traditional Healers: Intervention. http://www.siliconzoo.co.za/previews/thamba/healers.html.

Varga, C. A., and D. J. Veale. 1997. Isihlambezo: Utilization Patterns and Potential Health Effects of Pregnancy-Related Traditional Herbal Medicine. Social Science and Medicine 44(7): 911-924.

Veale, D. J., K. I. Furman, and D. W. Oliver. 1992. South African Traditional Herbal Medicines Used during Pregnancy and Childbirth. Journal of Ethnopharmacology 36(3): 185-191.

Veale, D. J., I. Havlik, L. C. Katsoulis, T. L. Kaido, N. S. Arangies, D. W. Olive, T. G. Dekker, K. B. Brookes, and O. V. Doudoukina. 1998. The Pharmacological Assessment of Herbal Oxytocics Used in South African Traditional Medicine. Biomarkers and Environment 2(2-3). http://www.cechtuma.cz/bioenv/1998/2-3/c216-en.html.

Wilkinson, D., L. Gcabashe, and M. Lurie. 1999. Traditional Healers as Tuberculosis Treatment Supervisors: Precedent and Potential. International Journal of Tuberculosis and Lung Disorders 3(9): 838-842.

World Bank, Sub-Saharan Africa. 2001. Indigenous Knowledge (IK) Program. http://www.worldbank.org/afr/ik/kmpacks.htm.

\section{Notes}

A flier advertising the services of a 'dokotela' (doctor) named Maama Asha Maraka (a woman from Uganda) that I picked up on the main street of the Zululand town Mtubatuba in November 2003 included the statement, in English, 'People with AIDS/HIV can be helped on symptoms.' The rest of the pamphlet was in Zulu and offered cures for all the symptoms of AIDS, plus everything else besides. Since Mtubatuba is home to many English-speaking medical researchers attached to the 
Hblabisa Hospital and the Africa Centre for Health and Population Studies, Maama Asha was wise to deflect inquiries about her capacities to treat AIDS.

Rian Malan has an account of an incident during a miners' strike when African workers treated with muthi designed to turn bullets into water encountered management's new riot control technology: the water cannon. The strikers' jubilation was short-lived when management returned to its old method of using live ammunition (Malan, 1990: 209).

There is no reason to presume that Africans working within the medical system as doctors, nurses, and technicians are completely severed from all cultural forms and practices of the world in which they live, nor that their professional practice and personal lives conform seamlessly with the ideological stipulations of 'scientific' medicine such that they would automatically treat all popular understandings of suffering and illness as 'superstition' - a superstition that they, as medical practitioners, are supposed to be above. A survey of black medical students' attitudes to witchcraft in the early 1980 s at the Medical University of South Africa, Medunsa, found that the majority of them did not doubt the powers of witches (Elliot, 1984). Many important questions concerning African medical practice in South Africa remain unexamined in the literature of medical anthropology, such as: How are meaningful diagnoses made and communicated to patients living in a world of witches? How are treatment options and drug-prescribing practices influenced by expectations deriving from 'traditional' medical experiences of doctors and patients? How are practices of self-medication among African patients shaped by lessons learned in consultations with Western and with traditional practitioners?

As of July 2001, the World Bank's Indigenous Knowledge Pack for South Africa contained little other than a summary of an article from the Sowetan reporting research from Stellenbosch University on the use of the 'African potato' in the treatment of HIV and other viral infections, with the following appended: 'Lesson: Combining Western and traditional medicines in treating terminal illnesses may help developing [sic] efficient treatments' (World Bank, Sub-Saharan Africa, 2001, emphasis in original). The African potato, Hypoxis hemerocallidea, has been hailed in the popular press as a 'miracle muthi' after tumor-suppressing and immunesystem-stimulating properties of its phenolic chemical constituents were isolated and tested, although as the chemist who initially identified them has noted: "with the present fragmentary knowledge regarding the effects on the human body of the complex mixture of compounds present in the whole extract of the Hypoxis plant, we would advise caution in hurriedly "taking to the bottle"" (Drewes and Horn, 2002: 4).

For surveys of debates on IKS, see Ellen and Harris (1996, 2000); Rouse (1999). For examples of attempts to make the notion of IKS relevant to South Africa, see Odora Hoppers (2002).

George Mukuka, IKS manager, National Research Foundation, July 19, 2001, personal communication.

See http://www.uct.ac.za/depts/pha/satmerg.htm. 
For a discussion of these options in the South African context, see Freeman and Motsei (1992).

The literature on traditional healing in South Africa has been mainly concerned with efforts to describe particular healing 'systems' in distinct ethnic/national groups (e.g., Ashton, 1943; H. Ngubane, 1977) or to construct a general account that can serve either as a reference point for those engaged with Western biomedicine (e.g., Conco, 1972; Hammond-Tooke, 1989; Hewson, 1998) or as a means by which respect can be accorded to African culture and the injuries of the past redressed (e.g., Gumede, 1990; Mutwa, 1969). In recent years, primarily in response to the tuberculosis and HIV/AIDS epidemics, a growing body of work has examined questions of how to integrate traditional healers into the biomedical system (e.g., Hopa, Simbayin, and Du Toit, 1998; Wilkinson, Gcabashe, and Lurie, 1999), although there are few studies of the attitudes and perceptions of physicians and other stakeholders in the biomedical system to traditional healing (Peltzer, 2001). Apart from an important body of work on the faith-healing communities of the AICs (Kiernan, 1990b; Oosthuizen, 1992; Oosthuizen et al., 1989), little has been written on urban innovations in healing (Farrand, 1980), the varieties of healing that do not conform with traditional notions and categories such as sangoma and inyanga, or the ways those healing categories and the practices associated with them have developed in nontraditional ways (Cocks and Dold, 2000).

Despite the extent and importance of this writing on customary law, many African legal scholars consider the legal foundations of customary law as it became institutionalised in the South African state to be contrary to the true interests and culture of Africans. See, e.g., Majeke (2002). For an account of the recognition of customary law, see Hahlo and Kahn (1960); also Chanock (2001).

For a description of a young man's experience at such a school in the 1990 s, see Ramphele (2002).

This issue proved a major bone of contention in discussions between the Department of Health and traditional-healing 'stakeholders.' At one meeting, on February 20, 2001 , in Pretoria, representatives of the department announced that healers would have to take a written exam prior to registration, a suggestion that outraged the less literate healers. The proposal was dropped (Katherine Lee, South African Traditional Healers' Alliance, personal communication). Since the knowledge embodied in traditional healing has never been transmitted by means of writing, such an examination would be a curious anomaly. An insight into difficulties with the issue of qualifications can be gleaned from the fact that the official web site of Thamba Administrators, a company set up to administer medical insurance plans for employers that cover the services of traditional healers (who are paid with vouchers), lists under 'Requirements' that healers 'must have the necessary qualifications as recognised by an approved traditional healers association,' and under 'Training' states, in boldface: 'We need more information about what training you require to become a Traditional Healer' (Thamba Administrators, 2001). The company was 
incorporated in January 1997 and the question remained unanswered four years later when I viewed their web site.

These groups have tended to be organised on ethnic lines. The two largest organisations, the Interim-Coordinating Council of Traditional Healers (predominantly Xhosa) and the Traditional Healers Organisation of South Africa (predominantly Zulu), have been at loggerheads in the battle for government recognition (Katherine Lee, South African Traditional Healers' Alliance, July 19, 2001 , personal communication).

To the best of my knowledge, the economics of fee setting among South African traditional healers has not been explored. In Central Africa, however, Kenneth Leonard has found that the custom of paying healers more if their treatments are successful produces an incentive for healers to strive to provide quality care (Leonard 2001a, 2001b).

A document issued in 2000 by the Professional Traditional Healers Register of South Africa (motto: 'Healers United for the Healing of South Africa and the World'), for example, notes that many forms of alternative medicine used in the West (e.g., 'Massage, Aromatherapy, Acupuncture, Reflexology, Bach Flower Remedies etc.') originated in Africa and are used by African traditional healers.

The five-year Strategic Framework plan devised by the national and provincial health departments, for example, makes no mention of traditional or spiritual healers at all. See Department of Health (1999).

The Department of Health's AIDS Strategy plan, for example, lists as goals: 'Collaborate with traditional healers to improve health care seeking behaviour for STDs' (Goal 2); 'Conduct research on the effectiveness of traditional medicines' (Goal 11) (Department of Health, 2000).

For an example of some of the reactions to this legislation from purveyors of 'complementary' medicines, consider this initialism: PHARMAPACT (Peoples Health Alliance Rejecting Medical Authoritarianism, Prejudice, and Conspiratorial Tyranny). 